\title{
The modified patient enablement instrument: a Portuguese cross-cultural adaptation, validity and reliability study
}

\author{
Mafalda Remelhe ${ }^{1}$, Pedro M Teixeira ${ }^{2}$, Irene Lopes ${ }^{3}$, Luís Silva ${ }^{2,4}$ and Jaime Correia de Sousa ${ }^{2,4}$
}

Enabling patients with asthma to obtain the knowledge, confidence and skills they need in order to assume a major role in the management of their disease is cost effective. It should be an integral part of any plan for long-term control of asthma. The modified Patient Enablement Instrument (MPEI) is an easily administered questionnaire that was adapted in the United Kingdom to measure patient enablement in asthma, but its applicability in Portugal is not known. Validity and reliability of questionnaires should be tested before use in settings different from those of the original version. The purpose of this study was to test the applicability of the mPEI to Portuguese asthma patients after translation and cross-cultural adaptation, and to verify the structural validity, internal consistency and reproducibility of the instrument. The mPEI was translated to Portuguese and back translated to English. Its content validity was assessed by a debriefing interview with 10 asthma patients. The translated instrument was then administered to a random sample of 142 patients with persistent asthma. Structural validity and internal consistency were assessed. For reproducibility analysis, 86 patients completed the instrument again 7 days later. Item-scale correlations and exploratory factor analysis were used to assess structural validity. Cronbach's alpha was used to test internal consistency, and the intra-class correlation coefficient was used for the analysis of reproducibility. All items of the Portuguese version of the mPEl were found to be equivalent to the original English version. There were strong item-scale correlations that confirmed construct validity, with a one component structure and good internal consistency (Cronbach's alpha $>0.8$ ) as well as high test-retest reliability (ICC $=0.85$ ). The $\mathrm{mPEl}$ showed sound psychometric properties for the evaluation of enablement in patients with asthma making it a reliable instrument for use in research and clinical practice in Portugal. Further studies are needed to confirm its responsiveness.

npj Primary Care Respiratory Medicine (2017) 27, 16087; doi:10.1038/npjpcrm.2016.87; published online 12 January 2017

\section{INTRODUCTION}

Assessment of patient enablement may prove to be an important component of effective asthma care, but it is important to know about the applicability of existing instruments in different cultural settings.

Asthma is a chronic respiratory disease affecting $1-18 \%$ of the population. ${ }^{1}$ In Portugal, the latest estimate of the prevalence of 'current asthma' is $6.8 \%$, similar in both men and women, ${ }^{2}$ whereas the estimate for 'lifelong asthma' is between 10.24 and $10.5 \%$. $^{2,3}$

International $^{1-6}$ and national ${ }^{7}$ guidelines recommend the assessment of asthma control at every visit. The assessment should include symptom control and the risk of adverse outcomes, as well as a discussion of treatment issues, including inhaler technique, adherence, and the presence of adverse effects, and the management of comorbidities that contribute to the burden of symptoms and poorer quality of life. ${ }^{1,6}$

Despite the availability of asthma management guidelines and asthma therapies of proven efficacy, the majority of patients do not achieve good asthma control. ${ }^{4,7-9}$ In Portugal it is estimated that $43 \%$ of patients have uncontrolled asthma, ${ }^{10}$ similar to results from recent studies in other countries. ${ }^{9}$

The reasons for poor asthma control include errors in diagnosis, smoking, comorbid rhinitis, incorrect choice of inhalers, poor inhaler technique, individual variation in response to treatment, patient beliefs and concerns, treatment adherence, increased exposure to environmental allergens, decreased access to good care, suboptimal self-management and low socioeconomic status. ${ }^{4,9-12}$

Effective asthma management and improved outcomes require a partnership between the patient and healthcare providers., ${ }^{1,8}$ Appropriate asthma self-management ${ }^{13,14}$ may be the most cost-effective way to reduce morbidity and mortality. ${ }^{1,9,15,16}$ This includes monitoring symptoms, controlling allergens, adhering to treatment and adjusting medicines when necessary. ${ }^{15}$

Enabling the person with asthma to assume a major role in the management of their disease is cost effective and should be an integral component of any plan for long-term management of asthma, in accordance with international and national recommendations. ${ }^{1,4}$

The Patient Enablement Instrument (PEI) is a self-administered questionnaire that was developed in the United Kingdom. ${ }^{17}$ The PEI is related to, but different from, measures of satisfaction. ${ }^{17}$ This is a widely accepted tool that has been validated in many cross-sectional studies. It has been translated and evaluated in several countries, including Portugal. It has high internal consistency and delivers consistent results. ${ }^{18-23}$

In 2006, the PEl was adapted by Haughney and collaborators for use in asthma management, creating the modified PEI (mPEI). ${ }^{24}$ The mPEI demonstrated similar internal consistency and external validity to the original. ${ }^{24}$

\footnotetext{
${ }^{1}$ School of Health Sciences, University of Minho, Braga, Portugal; ${ }^{2}$ Life and Health Sciences Research Institute (ICVS), School of Health Sciences, University of Minho, Braga, Portugal; ${ }^{3}$ Oceanos Family Health Unit, Porto, Portugal and ${ }^{4}$ Horizonte Family Health Unit, Porto, Portugal.

Correspondence: Pedro M Teixeira (teixeira.pms@gmail.com)

Received 24 November 2015; revised 31 October 2016; accepted 31 October 2016 
The $\mathrm{mPEl}$ has since been used in the United Kingdom and Portugal. ${ }^{24-26}$ In a Portuguese study, the instrument was translated and culturally adapted but no psychometric properties were assessed, hence the importance of the present study. ${ }^{26}$

The aim was to adapt the MPEI to Portuguese asthma patients and ensure it is a valid and reliable instrument. So, the objectives of this study were to test the applicability of the mPEl to Portuguese asthma patients after translation and cross-cultural adaptation, and to verify the structural validity, internal consistency and reproducibility.

\section{RESULTS}

Participants

The study included a random sample without replacement of 150 patients, aged 18 years old and over, with a diagnosis of persistent asthma. Initially a random group of 302 patients were approached for participation in the study and screened for exclusion criteria. From this group 80 patients had intermittent asthma and were not currently under chronic treatment with inhaler devices, 36 patients were unwilling to participate, 20 patients missed the first appointment, 10 patients were improperly diagnosed, 4 patients had cognitive impairment and 2 patients were unable to independently complete the questionnaire. In addition, 8 patients could not be reached (due to emigration and/or cancelling of telephone accounts). Although 150 patients were eligible for the study, only 142 patients could be recruited in time to participate in the study, $86(60.6 \%)$ of whom completed the mPEl in both $\mathrm{T} 1$ and $\mathrm{T} 2$.

The sample consisted of 65 men and 77 women. The age of the participants ranged from 19 to 88 . The demographic characteristics of the patients for both T1 and T2 are presented in Table 1.

The mean and s.d. of the mPEI (each item and total scale) at $\mathrm{T} 1$ and $\mathrm{T} 2$ are presented in Table 2 . The total score of the $\mathrm{mPEl}$ at $\mathrm{T} 1 \mathrm{had}$ a minimum of 0 (1.40\% of responses) and a maximum of 12 (19\% of responses). There were no floor or ceiling effects. At T2, the total score of the mPEI had a minimum of 0 and a maximum of 12 . Ceiling effect was observed in $24.40 \%$ of patients. There was no floor effect. The score for each item was significantly correlated with total $\mathrm{mPEI}$ score.

The suitability of data for factor analysis was assessed. Inspection of the correlation matrix revealed the presence of coefficients of 0.3 and above.

At T1, the KMO value was 0.85 and Bartlett's Test of Sphericity reached statistical significance $\left(X^{2}(15)=402, P=0.000\right)$, which

Table 1. Characteristics of participants at $\mathrm{T} 1$ and $\mathrm{T} 2$ (7 days later)

\begin{tabular}{|c|c|c|c|}
\hline $\begin{array}{l}\text { Characteristics of } \\
\text { patients }\end{array}$ & $T 1^{\mathrm{a}}(\mathrm{n}=142)$ & $T 2^{\mathrm{b}}(\mathrm{n}=86)$ & P-value \\
\hline Male/female, $n$ (\%) & $\begin{array}{c}65(45.8 \%) / 77 \\
(54.7 \%)\end{array}$ & $\begin{array}{c}33(38.4 \%) / 53 \\
(61.6 \%)\end{array}$ & 0.30 \\
\hline \multicolumn{4}{|l|}{ Age } \\
\hline $\begin{array}{l}\text { Mean } \pm \text { s.d. } \\
\text { Skewness (s.e.) } \\
\text { Kurtosis (s.e.) }\end{array}$ & $\begin{array}{c}49.3 \pm 17.0 \text { years } \\
-0.04(0.20) \\
-0.99(0.40)\end{array}$ & $\begin{array}{c}50.8 \pm 17.1 \text { years } \\
\quad-0.15(0.26) \\
-0.95(0.51)\end{array}$ & 0.52 \\
\hline \multicolumn{4}{|l|}{ Education level } \\
\hline$\leqslant 4$ years, $n(\%)$ & 53 (37.3\%) & 37 (43\%) & 0.39 \\
\hline 6 years, $n(\%)$ & 9 (6.30\%) & $5(5.80 \%)$ & 0.88 \\
\hline 9 years, $n$ (\%) & $17(12 \%)$ & 7 (8.10\%) & 0.35 \\
\hline 11 years, $n(\%)$ & $6(4.20 \%)$ & $3(3.50 \%)$ & 0.79 \\
\hline 12 years, $n(\%)$ & $26(18.3 \%)$ & $14(16.3 \%)$ & 0.70 \\
\hline$>12$ years, $n(\%)$ & $31(21.8 \%)$ & $20(23.3 \%)$ & 0.79 \\
\hline
\end{tabular}

meant that the levels of correlation between the items of the instrument were high enough to perform factor analysis on the sample. PCA revealed the presence of 1 component with an initial eigenvalue of 3.68 , explaining $61.3 \%$ of the variance, which consisted of all six items of the scale. Factor loadings are presented in Table 3. An inspection of the scree plot revealed a clear brake after the first component.

At T2, the KMO value was 0.82 and Bartlett's Test of Sphericity reached statistical significance $\left(X^{2}(15)=295, P=0.000\right)$, so the levels of correlation between the items of the instrument were enough to perform factor analysis on the sample. PCA revealed the presence of 1 component with eigenvalue exceeding 1 , explaining $63.1 \%$ of the variance, which consisted of all six items of the scale. Factor loadings are presented in Table 3. An inspection of the scree plot revealed a clear brake after the first component.

At T1, Cronbach's alpha was 0.87 , and 0.88 at T2. The values of item-total correlation were between 0.58 and 0.76 , indicating that the $\mathrm{mPEI}$ has good internal consistency (Table 4). The mPEI revealed high test-retest reliability $(\mathrm{ICC}=0.85$; confidence interval $95 \% ; 0.78$ to 0.90 ).

\section{DISCUSSION}

The purpose of this study was to perform a cross-cultural adaptation of the mPEl questionnaire to Portuguese and to examine the psychometric properties of the translated scale in a sample of Portuguese asthma patients. Careful linguistic translation is a necessary but not sufficient condition for the application

Table 2. Item and scale descriptives and item-scale correlations of the Portuguese $\mathrm{mPEl}$ at $\mathrm{T} 1$ and $\mathrm{T} 2$ ( 7 days later)

\begin{tabular}{|c|c|c|c|c|c|c|}
\hline \multirow[t]{2}{*}{ mPEl item } & \multicolumn{3}{|c|}{$T 1^{\mathrm{a}}(\mathrm{N}=142)$} & \multicolumn{3}{|c|}{$T 2^{\mathrm{b}}(\mathrm{N}=86)$} \\
\hline & Mean & s.d. & $\begin{array}{l}\text { Correlation with } \\
\text { total mPEI score }\end{array}$ & Mean & s.d. & $\begin{array}{c}\text { Correlation } \\
\text { with total } \mathrm{mPEI} \\
\text { score }\end{array}$ \\
\hline Item 1 & 1.23 & 0.71 & $\rho(140)=0.77^{*}$ & 1.34 & 0.68 & $\rho(84)=0.84^{*}$ \\
\hline Item 2 & 1.39 & 0.67 & $\rho(140)=0.75^{*}$ & 1.50 & 0.61 & $\rho(84)=0.79 *$ \\
\hline Item 3 & 1.43 & 0.64 & $\rho(140)=0.80^{*}$ & 1.50 & 0.59 & $\rho(84)=0.80^{*}$ \\
\hline Item 4 & 1.26 & 0.68 & $\rho(140)=0.83^{*}$ & 1.37 & 0.60 & $\rho(84)=0.79^{*}$ \\
\hline Item 5 & 1.20 & 0.66 & $\rho(140)=0.84^{*}$ & 1.31 & 0.64 & $\rho(84)=0,77^{*}$ \\
\hline Item 6 & 1.33 & 0.65 & $\rho(140)=0.71^{*}$ & 1.41 & 0.64 & $\rho(84)=0.77^{*}$ \\
\hline Total & 7.85 & 3.13 & & 8.43 & 2.98 & \\
\hline
\end{tabular}

Table 3. Principal component analysis of the Portuguese mPEl for T1 and $\mathrm{T} 2$ (7 days later)

\begin{tabular}{|c|c|c|c|c|}
\hline \multicolumn{3}{|c|}{$T 1^{\mathrm{a}}$} & \multicolumn{2}{|c|}{$T 2^{\mathrm{b}}$} \\
\hline mPEI & $\begin{array}{l}\text { Loading } \\
\text { factors }\end{array}$ & Communalities & $\begin{array}{l}\text { Loading } \\
\text { factors }\end{array}$ & Communalities \\
\hline Item 1 & 0.85 & 0.57 & 0.84 & 0.71 \\
\hline Item 2 & 0.83 & 0.55 & 0.81 & 0.66 \\
\hline Item 3 & 0.81 & 0.66 & 0.83 & 0.68 \\
\hline Item 4 & 0.76 & 0.69 & 0.78 & 0.62 \\
\hline Item 5 & 0.75 & 0.71 & 0.76 & 0.58 \\
\hline Item 6 & 0.71 & 0.50 & 0.74 & 0.54 \\
\hline
\end{tabular}




\begin{tabular}{|c|c|c|c|c|c|c|c|}
\hline Item 1 & 0.64 & 0.86 & 0.75 & 0.85 & 0.67 & 0.50 & 0.79 \\
\hline Item 2 & 0.63 & 0.86 & 0.71 & 0.86 & 0.63 & 0.44 & 0.76 \\
\hline Item 5 & 0.76 & 0.84 & 0.66 & 0.87 & 0.77 & 0.65 & 0.85 \\
\hline \multirow[t]{2}{*}{ Item 6} & 0.58 & 0.87 & 0.63 & 0.87 & 0.69 & 0.53 & 0.80 \\
\hline & & Cronbach's alpha & & Cronbach's alpha & ICC & Lower & Upper \\
\hline Score & & 0.87 & & 0.88 & 0.85 & 0.76 & 0.90 \\
\hline
\end{tabular}

of a patient-outcome instrument in different population, in a different culture, speaking a different language. The evaluation of psychometric properties is fundamental to support its crosscultural application.

\section{Main findings}

This study revealed good psychometric properties of the Portuguese $\mathrm{mPEl}$. The results of the item-scale correlation and the principal component analyses performed using an exploratory approach support the internal construct validity of the MPEI as a measure of only one component-enablement. High correlations between items and the total score and principal factor demonstrated the relevance and importance of items.

The internal consistency was good suggesting the items measure the same construct and indicates that the scale is sufficiently reliable for use as an outcome variable in clinical research. Moreover, the instrument revealed high test-retest reliability, an aspect not tested in the original study or since. This is also supported by the fact that mPEl scores were reproducible between $\mathrm{T} 1$ and $\mathrm{T} 2$. $^{14,23}$

The mean mPEl score in this study was higher than that previously reported in Portugal. ${ }^{26}$ There was a tendency for ceiling effects in T1 and in T2. Over 20\% of patients scored the highest score, which could compromise the sensitivity of the instrument. However, as only $60.6 \%$ of patients participated in the data collection of T2, this could explain the observation. Patients who are more motivated and concerned with health issues may have a higher enablement score.

Interpretation of findings in relation to previously published work The Portuguese translation of the mPEl has a good correspondence to the original version, and the structure of the questions is simple and easily understood. ${ }^{24}$ The cultural adaptation did not present any difficulties, and the patients could comprehend the constructs involved.

Strengths and limitations of this study

The responsiveness of the instrument, that is, the change in score over time in case of a meaningful change, is yet to be evaluated. Further studies are needed to help to establish it as an appropriate outcome measure in the long-term management of asthma.

Implications for future research, policy and practice

The assessment of psychometric properties recommends the use for clinical practice of the Portuguese mPEI version.

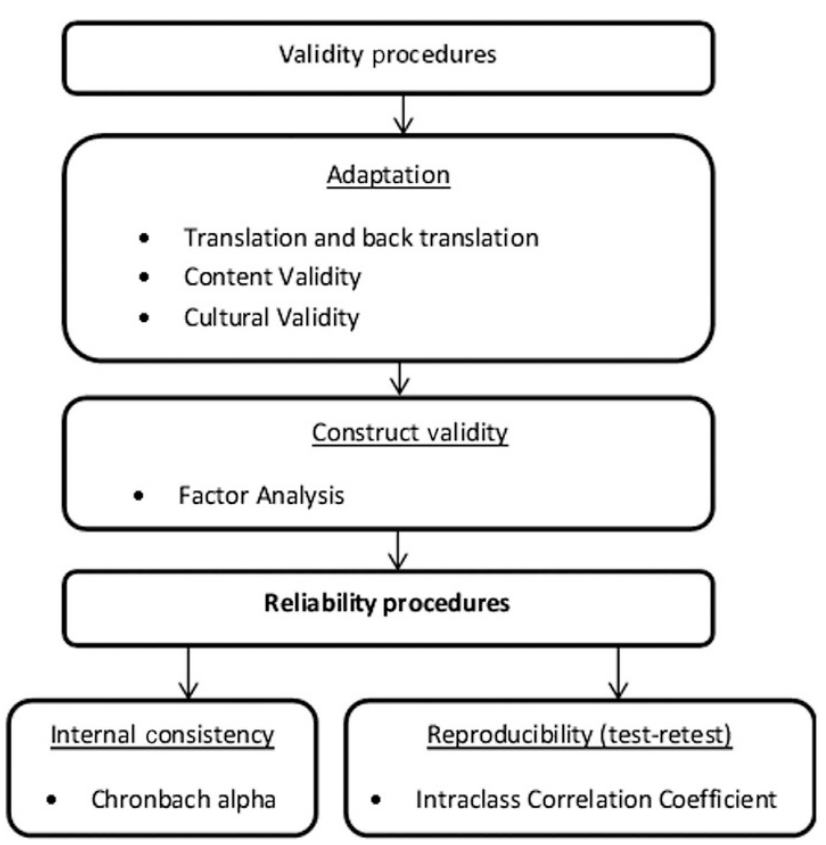

Figure 1. A flow chart depicting the process used for validation and reliability study of the Portuguese mPEl.

\section{Conclusions}

In conclusion, the Portuguese mPEl is semantically equivalent to the original instrument. It presented satisfactory measurement properties according to cross-cultural validity, reproducibility, internal consistency and factor analysis. Additional research will test its responsiveness and define it as a useful outcome measure to consider in the long-term management of asthma.

\section{MATERIALS AND METHODS}

The methods used to adapt and validate the mPEl included the following: linguistic and cultural adaptation, construct validity and reliability tests. A flow chart depicting the processes used to examine the validity of the SQ is presented in Figure 1. Analyses were performed using Statistical Package for the Social Sciences (SPSS) software for Macintosh Operative System Version 22.0 (SPSS, IBM Company, Chicago, IL, USA).

Translation and cultural validity

Permission from the authors of the MPEl was obtained in order to use and translate it into Portuguese. The translation was developed by 
forward-backward translations from the original English version. There were two independent translations, produced by two native Portuguesespeaking translators fluent in English. Both versions were compared by a panel of six general practitioners and, after consensus the instrument was prepared in a single document. This consensus version was then translated back to English, by two native English-speaking general practitioners fluent in Portuguese, without prior knowledge of the original version. This was then compared with the original, to ensure conceptual and semantic equivalence. Cognitive debriefing of the Portuguese version of the $\mathrm{mPEI}$ was performed with 10 asthma patients in order to evaluate the adequacy of the format and presentation and to assess the clarity and interpretation of each item and response option. Each item was understood and correctly interpreted by all patients. A panel consisting of six Family Physicians agreed that the Portuguese version demonstrated semantic and grammatical equivalence.

\section{Construct validity}

The internal construct validity of the scale was first evaluated by Spearman's correlation coefficient between the item and the scale score. An item should be substantially linearly related $(\rho \geqslant 0.4)$ to the underlying concept (total score) being measured. ${ }^{27,28}$ To verify construct validity, the factorial design of the Portuguese version of the MPEI was analysed in a stepwise procedure. At both T1 and T2, two measures were used to assess sampling adequacy-Kaiser-Meyer-Olkin measure (KMO) and Bartlett's test of sphericity. KMO is a measure of sampling adequacy calculated for both the entire correlation matrix and each variable individually. KMO values above 0.60 indicate that the sample is adequate for factor analysis. ${ }^{27,28}$ Bartlett's test indicates the strength of the association between variables. It tests the null hypothesis that there is no association among the variables, only of each variable with itself. Factor analysis is only indicated when the null hypothesis is rejected. Assuming adequacy of the sample, a principal component analysis (PCA) with varimax rotation was also conducted. The number of factors extracted was determined using the Kaiser method, i.e., according to initial eigenvalues (retention if $>1.0$ ) and the visualisation of the Cattell's scree plot in order to assess the amount of variance accounted for by a factor. ${ }^{27,28}$ All factor loadings (i.e., correlations of an item with a factor) greater than 0.50 were considered relevant. ${ }^{27,28}$

\section{Reliability study}

The temporal stability of both scales was assessed by test-retest by asking participants to complete both instruments 7 days after the first interview. The change in mean scores between the test and the retest was evaluated by the intra-class correlation coefficient (ICC) with values ranging from 0 (no stability) to 1 (perfect stability). ${ }^{27,28}$ Cronbach's alpha was used to examine the internal consistency of the instrument. It was considered that values $>0.70$ represent acceptable consistency. ${ }^{27,28}$ Corrected item-total correlation of 0.30 or higher was considered acceptable for each item. ${ }^{27,28}$

\section{Participants}

This study was conducted in two Family Health Units (FHU), in Matosinhos, Portugal during February and March 2015. The sample was randomly selected without replacement from the local database of 620 asthma patients. Asthma was classified as persistent according to the indication for chronic therapy with inhaled corticosteroids. The sample size was calculated to assure 20 observations per item. ${ }^{23}$ Patients with cognitive impairment, kyphoscoliosis, absence of one lung, lung cancer, pregnancy and those unable to provide informed consent, or unable to independently complete the questionnaire were excluded before randomisation. Randomisation was performed using the number generator tool from SPSS. First, 10 patients were randomly selected to assess translation and cultural validation. These patients were later excluded from the randomisation. Second, 150 patients were randomly selected for interview. No financial compensation was provided for participation. The study was explained to each patient by telephone. The patients who agreed to participate were invited to come to the FHU at a time of their choosing for an interview in order to verify their eligibility to enter the study and to review the consent form. During the interview, demographic data, including gender, age and educational level, were collected on a form, identified with a unique number to preserve confidentiality. Each patient was scheduled for a second interview 7 days later (T2), at the FHU, at a time of their choosing.
Questionnaire: modified patient enablement instrument

The $\mathrm{mPEl}$ is a six-item questionnaire. Each item is scored in a Likert-type scale from 0 ('same or less' or 'not applicable') to 2 ('much better'). There is a minimum score of 0 and a maximum score of 12 . A higher score reflects higher patient enablement. The mPEl has good internal consistency with a reported Cronbach's alpha coefficient of $0.92 .{ }^{14}$ The translated version to Portuguese may be found in Supplementary Appendix 1.

\section{Ethical approval}

This study was approved by the Ethics Sub-committee for the Health and Life Sciences of University of Minho and by the Ethics Committee of the Local Health Authority in Matosinhos (053/CE/JAS).

\section{ACKNOWLEDGEMENTS}

We thank Johm Haughney for consenting to translate and use the modified PEI. We thank Ana Figueiredo for the initial protocol design and ethical approvals for the study. We also thank John Yaphe for help with the back translation of the instrument and editing of the final report.

\section{CONTRIBUTIONS}

MR designed the study, collected the data, contributed to the interpreted results and drafted the manuscript. PMT performed the data analysis and wrote parts of the methods, results and discussion. IL contributed to study design, collected the data and reviewed the manuscript. LS contributed to the study design, collected data and reviewed the manuscript. JCS conceived the idea for the study, contributed to the study design, contributed to the interpretation of results and reviewed the manuscript. All authors read and approved the final version of the manuscript.

\section{COMPETING INTERESTS}

The authors declare no conflict of interest.

\section{FUNDING}

Financial support for this work was provided by FEDER funds through the Operational Programme Competitiveness Factors - COMPETE and National Funds through FCTFoundation for Science and Technology under the project POCI-01-0145-FEDER-007038, and by the project NORTE-01-0145-FEDER-000013, supported by Norte Portugal Regional Operational Programme (NORTE 2020), under the PORTUGAL 2020 Partnership Agreement, through the European Regional Development Fund (ERDF).

\section{REFERENCES}

1. Global Initiative for Asthma. Global Strategy for Asthma Management and Prevention. Available at www.ginasthma.org (2015).

2. Sa-Sousa, A. et al. Prevalence of asthma in Portugal-The Portuguese National Asthma Survey. Clin. Transl. Allerg. 2, 15 (2012).

3. Correia de Sousa, J., Espírito-Santo, M., Colaço, T., Almada-Lobo, F. \& Yaphe, J. Asthma in an urban population in Portugal: a prevalence study. BMC Pub. Health 11, 347 (2011).

4. Haughney, J. et al. Achieving asthma control in practice: understanding the reasons for poor control. Respir. Med. 12, 1681-1693 (2008).

5. Pinnock, $\mathrm{H}$. et al. Implementing supported self-management for asthma: a systematic review and suggested hierarchy of evidence of implementation studies. BMC Med. 13, 127 (2015).

6. Pinnock, H. et al. Setting the standard for routine asthma consultations: a discussion of the aims, process and outcomes of reviewing people with asthma in primary care. Prim. Care Respir. J. 19, 75-83 (2010).

7. Direç̧ão-Geral da Saúde. Approach and asthma control: standard clinical guideline no. 016/2011, de 27/09/2011, reviewed on 14/06/2012.

8. Horne, R. \& Weinman, J. Self-regulation and self-management in asthma: exploring the role of illness perceptions and treatment beliefs in explaining nonadherence to preventer medication. Psychol. Health 17, 17-32 (2002).

9. Cazzoletti, L. et al. Asthma control in Europe: a real-world evaluation based on an international population-based study. J. Allerg. Clin. Immunol. 120, 1360-1367 (2007).

10. Sá-Sousa, A. et al. Asthma control in the Portuguese National Asthma Survey. Rev Port Pneumol. 21, 209-213 (2015).

11. Partridge, M. R., van der Molen, T., Myrseth, S. E. \& Busse, W. W. Attitudes and actions of asthma patients on regular maintenance therapy: the INSPIRE study. BMC Pulmon. Med. 6, 13 (2006). 
12. Wisnivesky, J. P., Lorenzo, J., Feldman, J. M., Leventhal, H. \& Halm, E. A. The relationship between perceived stress and morbidity among adult inner-city asthmatics. J. Asthma 47, 100-104 (2010).

13. Barlow, J., Wright, C., Sheasby, J., Turner, A. \& Hainsworth, J. Self-management approaches for people with chronic conditions: a review. Patient Educ. Counsell. 48, 177-187 (2002).

14. Newman, S., Steed, L. \& Mulligan, K. Self-management interventions for chronic illness. Lancet 364, 1523-1537 (2004).

15. Londoño, A. M. M. \& Schulz, P. J. Influences of health literacy, judgment skills, and empowerment on asthma self-management practices. Patient Educ. Counsell. 98, 908-917 (2015).

16. Lahdensuo, A. Guided self management of asthma-how to do it. BMJ $\mathbf{3 1 9}$, 759 (1999).

17. Howie, J. G., Heaney, D. J., Maxwell, M. \& Walker, J. J. A comparison of a Patient Enablement Instrument (PEI) against two established satisfaction scales as an outcome measure of primary care consultations. Fam. Pract. 15, 165-171 (1998).

18. Kurosawa, S. et al. Two principal components, coping and independence, comprise patient enablement in Japan: cross sectional study in Tohoku area. Tohoku J. Exp. Med. 227, 97-104 (2012).

19. Brusse, C. J. \& Yen, L. E. Preferences, predictions and patient enablement: a preliminary study. BMC Fam. Pract. 14, 116 (2013).

20. Hudon, C., Fortin, M., Rossignol, F., Bernier, S. \& Poitras, M. E. The Patient Enablement Instrument-French version in a family practice setting: a reliability study. BMC Fam. Pract. 12, 71 (2011).

21. Mercer, S. W., Jani, B. D., Maxwell, M., Wong, S. Y. \& Watt, G. C. Patient enablement requires physician empathy: a cross-sectional study of general practice consultations in areas of high and low socioeconomic deprivation in Scotland. BMC Fam. Pract. 13, 6 (2012).
22. Pintalhão, I., Botas, P., Pereira, C. \& Santiago, L. M. Desenvolvimento de Tradução para Português do Patient Enablement Instrument. RevADSO 2, 18-22 (2013).

23. Lam, C. L., Yuen, N. Y., Mercer, S. W. \& Wong, W. A pilot study on the validity and reliability of the Patient Enablement Instrument (PEI) in a Chinese population. Fam. Pract. 27, 395-403 (2010).

24. Haughney, J., Cotton, P., Rosen, J. P., Morrison, K. \& Price, D. The use of a modification of the Patient Enablement Instrument in asthma. Prim. Care Respir. J. 16, 89-92 (2007).

25. Ryan, D. et al. Clinical and cost effectiveness of mobile phone supported self monitoring of asthma: multicentre randomised controlled trial. BMJ 344, 1756 (2012).

26. Correia de Sousa, J. et al. Asthma control, quality of life, and the role of patient enablement: a cross-sectional observational study. Prim. Care Respir. J. 22 181-187 (2013)

27. Murphy, K. R. \& Davidshofer, C. O. in Psychological Testing: Principles and Applications 6th edn (Prentice Hall, 2004).

28. Nunnally, J. \& Bernstein, I. Psychometric Theory 3rd edn (McGraw Hill, 1994).

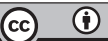

This work is licensed under a Creative Commons Attribution 4.0 International License. The images or other third party material in this article are included in the article's Creative Commons license, unless indicated otherwise in the credit line; if the material is not included under the Creative Commons license, users will need to obtain permission from the license holder to reproduce the material. To view a copy of this license, visit http://creativecommons.org/licenses/ by/4.0/

(c) The Author(s) 2017

Supplementary Information accompanies the paper on the npj Primary Care Respiratory Medicine website (http://www.nature.com/npjpcrm) 